\title{
Sequestering $\mathrm{CO}_{2}$ by Mineralization into Useful Nesquehonite-Based Products
}

\begin{abstract}
Fredrik Paul Glasser ${ }^{1 *}$, Guillaume Jauffret ${ }^{1}$, Jennie Morrison ${ }^{1}$, Jose-Luis Galvez-Martos ${ }^{2}$, Naomi Patterson ${ }^{2}$ and Mohammed Salah-Eldin Imbabi ${ }^{2}$
\end{abstract}

${ }^{1}$ Department of Chemistry, University of Aberdeen, Aberdeen, UK, ${ }^{2}$ School of Engineering, University of Aberdeen, Aberdeen, UK

The precipitation of magnesium hydroxy-carbonate hydrates has been suggested as a route to sequester $\mathrm{CO}_{2}$ into solids. We report the development of self-cementing compositions based on nesquehonite, $\mathrm{MgCO}_{3} \cdot 3 \mathrm{H}_{2} \mathrm{O}$, that are made from $\mathrm{CO}_{2}$-containing gas streams, the $\mathrm{CO}_{2}$ being separated from other gases by its high solubility in alkaline water, while magnesium is typically provided by waste desalination brines. Precipitation conditions are adjusted to optimize the formation of nesquehonite and the crystalline solid can readily be washed free of chloride. Products can be prepared to achieve self-cementation following two routes: (i) thermal activation of the nesquehonite then rehydration of the precursor or (ii) direct curing of a slurry of nesquehonite. The products thus obtained contain $~ 30$ wt $\% \mathrm{CO}_{2}$ and could form the basis for a new generation of lightweight, thermally insulating boards, blocks, and panels, with sufficient strength for general construction.

Renato Baciocchi, University of Rome

"Tor Vergata", Italy

Reviewed by: Carlos Rodriguez-Navarro, Universidad de Granada, Spain

Raffaella Pomi

Sapienza Università di Roma, Italy

*Correspondence:

Fredrik Paul Glasser f.p.glasser@abdn.ac.uk

Specialty section: This article was submitted to Carbon Capture, Storage, and Utilization, a section of the journal Frontiers in Energy Research

Received: 05 November 2015 Accepted: 25 January 2016 Published: 11 February 2016

Citation: Glasser FP, Jauffret G, Morrison J, Galvez-Martos J-L, Patterson N and Imbabi MS-E (2016) Sequestering $\mathrm{CO}_{2}$ by Mineralization into Useful Nesquehonite-Based Products.

Front. Energy Res. 4:3. doi: 10.3389/fenrg.2016.00003
Keywords: $\mathrm{CO}_{2}$ sequestration, desalination brines, mineralization, magnesium carbonates, construction products

\section{INTRODUCTION}

In order to mitigate the impacts of the continuously rising atmospheric $\mathrm{CO}_{2}$ levels (Earth System Research Laboratory, 2016), short- to medium-term measures are needed to cope with increasing $\mathrm{CO}_{2}$ emissions, while, in the longer term, strategies have to be developed to decarbonize society. The conventional approach to the sequestration of carbon dioxide involves the separation of $\mathrm{CO}_{2}$ from other gases, its liquefaction, transportation, and storage underground; the technology is well known and several large scale projects have been reported (Global CCS Institute, 2016). However, the cost of such process is at present still high and some uncertainties regarding the permanence of storage sites for liquid $\mathrm{CO}_{2}$ remain.

An alternative approach to achieve $\mathrm{CO}_{2}$ sequestration is to use mineralization, i.e., to make solid products related in composition, structure, and engineering properties to naturally occurring minerals while insuring a permanent and safe storage of the $\mathrm{CO}_{2}$ (Haywood et al., 2001; Lackner, 2002; Mazzotti et al., 2005; Teir et al., 2007; Styring et al., 2011; Olajire, 2013). For this reason, we have considered "MHCH" (shorthand for magnesium hydroxy-carbonate hydrate) phases, which exist as natural minerals and/or synthesis products, to be suitable targets for mineralization; Table $\mathbf{1}$ lists the name, formula, and composition of the most common $\mathrm{MHCH}$ phases. The fact that these phases, like their natural analogs, can be used by the industry (Constantz et al., 2010; Hull et al., 2011; Camire et al., 2012; Unluer and Al-Tabbaa, 2013) is important as a favorable economic balance is necessary to make any industrial $\mathrm{CO}_{2}$ sequestration process viable on the long term. 
TABLE 1 | Commonly synthesized $\mathrm{MHCH}$ phases.

\begin{tabular}{llccc}
\hline \multirow{2}{*}{ Name } & \multicolumn{1}{c}{ Formula } & \multicolumn{3}{c}{ Composition (wt\%) } \\
\cline { 3 - 5 } & & $\mathbf{M g O}$ & $\mathbf{C O}_{2}$ & $\mathbf{H}_{2} \mathbf{O}$ \\
\hline Nesquehonite & $\mathrm{MgCO}_{3} \cdot 3 \mathrm{H}_{2} \mathrm{O}$ & 29.1 & 31.8 & 39.1 \\
Dypingite & $\mathrm{Mg}_{5}\left(\mathrm{CO}_{3}\right)_{4}(\mathrm{OH})_{2} \cdot 5 \mathrm{H}_{2} \mathrm{O}$ & 41.5 & 36.2 & 22.3 \\
Hydromagnesite & $\mathrm{Mg}_{5}\left(\mathrm{CO}_{3}\right)_{4}(\mathrm{OH})_{2} \cdot 4 \mathrm{H}_{2} \mathrm{O}$ & 43.1 & 37.6 & 19.3
\end{tabular}

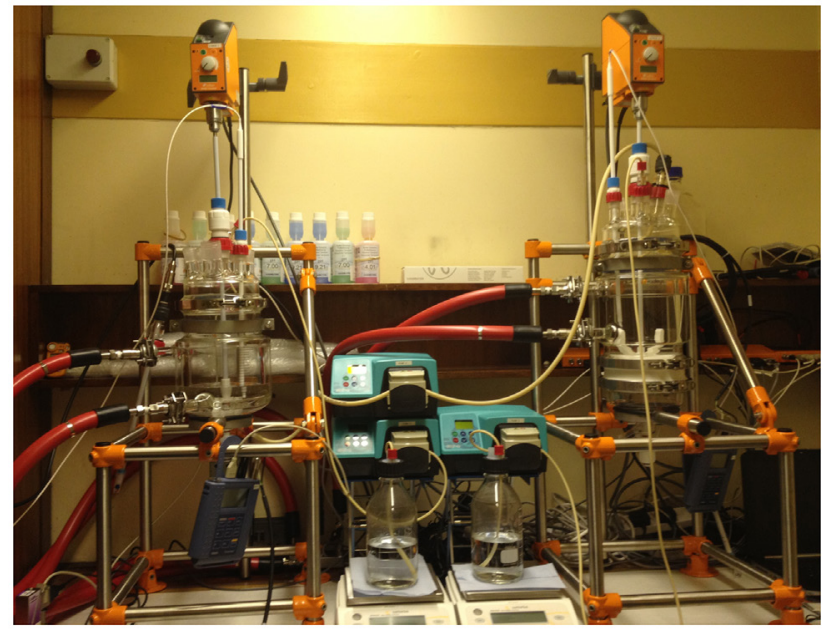

FIGURE 1 | Photo of the lab-scale reactor used for the synthesis of MHCH phases (the total height is about $1.3 \mathrm{~m}$ and the two doublewalled reactors have a $2-L$ internal capacity).

Our objective was to develop a process, from collection of $\mathrm{CO}_{2}$ to product, where previous separation from other gases is not required while synthesizing products with the following characteristics:

- Low initial cost, using where possible waste materials.

- Making products that could enter established large volume markets, of which building and construction seemed a potential target.

- Developing functional products which look and are handled like competitive materials, concentrating on replacing traditional materials with high embodied energy costs.

This contribution presents our progress to date and describes briefly future plans.

\section{MATERIALS AND METHODS}

A lab-scale reactor (Figure 1) allowing the control and recording of experimental parameters for batch syntheses (e.g., addition rates of reagents, reaction temperature, etc.) was designed in consultation with Radleys (UK). When using a commercial gas cylinder as the source of $\mathrm{CO}_{2}$, reaction occurs in two stages: (i) a dissolution stage in which $\mathrm{CO}_{2}$ is sparged in a solution kept at an alkaline $\mathrm{pH}$ with $\mathrm{NaOH}$ and (ii) a second stage in which the carbonate/bicarbonate solution obtained in the first stage reacts with a $\mathrm{Mg}$-containing solution, e.g., $\mathrm{MgCl}_{2}$ in most cases. In the trials described here, the first stage was replaced by the direct use of an aqueous solution of $\mathrm{NaHCO}_{3}+\mathrm{Na}_{2} \mathrm{CO}_{3}$. The second stage typically lasts $4 \mathrm{~h}$, starting from the addition of the $\mathrm{Mg}$-rich solution to the $\mathrm{CO}_{2}$-rich solution (addition time of $30 \mathrm{~min}$ ), with constant stirring at room temperature (i.e., $20-25^{\circ} \mathrm{C}$ ) and ambient pressure (i.e., $1 \mathrm{~atm}$ ) prior to washing and filtering the nesquehonite product. The holding stage allows crystallization to complete thus producing a coarse and readily filterable product. The yield of the reaction was calculated on the basis of recovered $\mathrm{Mg}$, which was determined by atomic absorption using a Varian AAS. The concentrations of $\mathrm{MgCl}_{2}$ and $\mathrm{Na}_{2} \mathrm{CO}_{3}+\mathrm{NaHCO}_{3}$ were $\sim 0.1-0.2 \mathrm{~mol} \mathrm{~L}^{-1}$ and all experiments were performed with an equimolar $\mathrm{Mg}: \mathrm{CO}_{2}$ ratio. The thermal analysis of the solid product was performed in static air in ovens and with a Stanton Redcroft DTA/TG apparatus typically at $5-10^{\circ} \mathrm{C} \mathrm{min}^{-1}$ under flowing nitrogen atmosphere (at $\sim 50-60 \mathrm{~mL} \mathrm{~min}^{-1}$ ).

Cubes of nesquehonite-based products were prepared using the following two methods: (i) nesquehonite is thermally activated between 100 and $250^{\circ} \mathrm{C}$ then the resulting solid is mixed with water, the product shaped then cured under humid conditions at ambient temperature and (ii) nesquehonite is mixed directly with water, the product is then shaped and cured under humid conditions at $60-80^{\circ} \mathrm{C}$. The compressive strength of the cubes was measured with a Hounsfield universal press using a loading speed of $1 \mathrm{~mm} \mathrm{~min} \mathrm{~m}^{-1}$ and a $10-\mathrm{kN}$ sensor. Thermal conductivity was measured with a Lasercomp FOX 603 Heat Flow Meter using a reduced-area multi-thickness measurement method (Patterson, under review $)^{1}$, which accounts for the effects of resistance to heat flow at the interface between the apparatus and the sample surface (Tleoubaev and Brzezinski, 2008) but uses a reduced sample size and so requires less material.

$\mathrm{X}$-ray diffraction (Panalytical X'Pert Pro using $\mathrm{Cu}-\mathrm{K}_{\alpha}$ radiation; power parameters were $45 \mathrm{kV}$ and $40 \mathrm{~mA}$ ) was used at the different stages of the process to characterize the solids formed while their morphology was assessed by Scanning Electron Microscopy (Hitachi S-520 using $20 \mathrm{kV}$ acceleration voltage).

\section{RESULTS}

\section{Production of Nesquehonite}

Nesquehonite was successfully obtained as the only solid phase using the Radleys reactor. Figure 2 shows the typical product morphology of sharply faceted long needles. The X-ray powder diffraction pattern of nesquehonite (Figure 3) conforms to that reported in the literature [e.g., Kloprogge et al. (2003) or Ma and Yoon (2013)].

With the experience of operating the Radleys reactor, it was found that precipitation conditions for making nesquehonite were relatively robust and reproducible in the range $20-25^{\circ} \mathrm{C}$. Therefore, a larger facility, which is composed of a $\sim 50-\mathrm{L}$ plastic tank equipped with a pump and a motorized stirrer, was used to make nesquehonite in kilogram batches using $\mathrm{Na}_{2} \mathrm{CO}_{3}, \mathrm{NaHCO}_{3}$, and $\mathrm{MgCl}_{2}$. Yields calculated on the basis of recovered $\mathrm{Mg}$ were

${ }^{1}$ Patterson, N., Yoon, S., Macphee, D. E., and Imbabi, M. S. The cuboid method for measurement of thermal properties of cement-based materials using the guarded heat flow meter. (under review, Constr. Build. Mater, 2015). 
typically around $75-80 \%$ and did not differ significantly from those obtained in the Radleys reactor; the product could in both cases be made phase pure and with the same morphology.

\section{Properties of Nesquehonite}

\section{Thermal Decomposition of Nesquehonite}

The thermal analysis of nesquehonite shows that volatiles, i.e., water and carbon dioxide, are lost in stages beginning at about

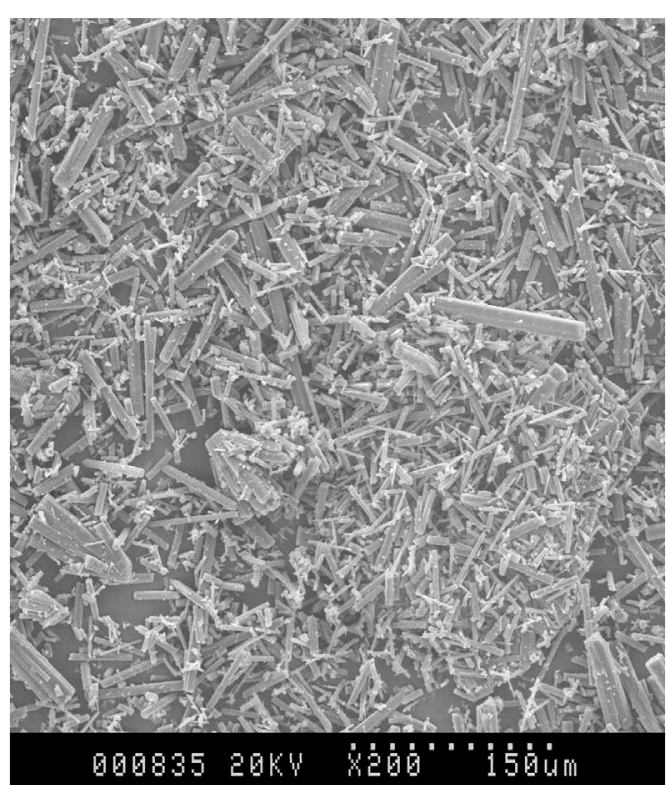

FIGURE 2 | Typical low magnification SEM photo of nesquehonite, $\mathrm{MgCO}_{3} 3 \mathrm{H}_{2} \mathrm{O}$ (synthesis conditions: $25^{\circ} \mathrm{C}, 4 \mathrm{~h}, 0.1 \mathrm{~mol}$ of $\mathrm{MgCl}_{2}$ and $\mathrm{Na}_{2} \mathrm{CO}_{3}$, total volume $\left.1.1 \mathrm{~L}\right)$. $100^{\circ} \mathrm{C}$ (Dell and Weller, 1959; Davies and Bubela, 1973; Lanas and Alvarez, 2004; Vagvolgyi et al., 2008; Ballirano et al., 2010; Jauffret et al., 2015). The low temperature decomposition stages (below $250^{\circ} \mathrm{C}$ ) are of most interest to a thermal activation process that also avoids loss of structural $\mathrm{CO}_{2}$. Three incompletely resolved stages of water loss occur in the course of DTA (Figure 4). The nesquehonite structure begins to break down during the loss of its first water molecule and the resulting product obtained at about $2 \mathrm{H}_{2} \mathrm{O}$ is an ill-crystallized phase we termed "phase X" as its $\mathrm{X}$-ray diffraction pattern is unlike any others reported for known $\mathrm{MHCH}$ phases, including that of barringtonite, which also has the formula $\mathrm{MgCO}_{3} \cdot 2 \mathrm{H}_{2} \mathrm{O}$ (Jauffret et al., 2015).

\section{Reconstitution of Nesquehonite}

One of the interesting characteristics of the thermally activated solids is that, upon mixing with water and allowing the wet paste to age at $\sim 20-25^{\circ} \mathrm{C}$, nesquehonite can be regenerated (Morrison et al., 2014; Jauffret et al., 2015). This suggests that sufficient structural motifs of nesquehonite are preserved during thermal activation to facilitate its reformation. The morphology of the precursor nesquehonite is certainly well preserved throughout the decomposition and subsequent reconstitution so that the morphology of the reconstituted product resembles that of the precursor. However, considerable heat is released in the course of reconstitution and recrystallization. The reconstitution reaction is cementitious and is initiated spontaneously by mixing the solid precursor powder with water and curing at room temperature, preferably with retention of water, for several hours.

\section{Stability of Nesquehonite}

Although nesquehonite persists up to $100^{\circ} \mathrm{C}$, it is unstable upon prolonged storage in moist atmospheres at temperatures above $60^{\circ} \mathrm{C}$. Additional data on its persistence and the extent of the hysteresis loop between $\mathrm{P} / \mathrm{T}$ conditions for hydration-dehydration cycles have been reported (Morgan et al., 2015). Nesquehonite

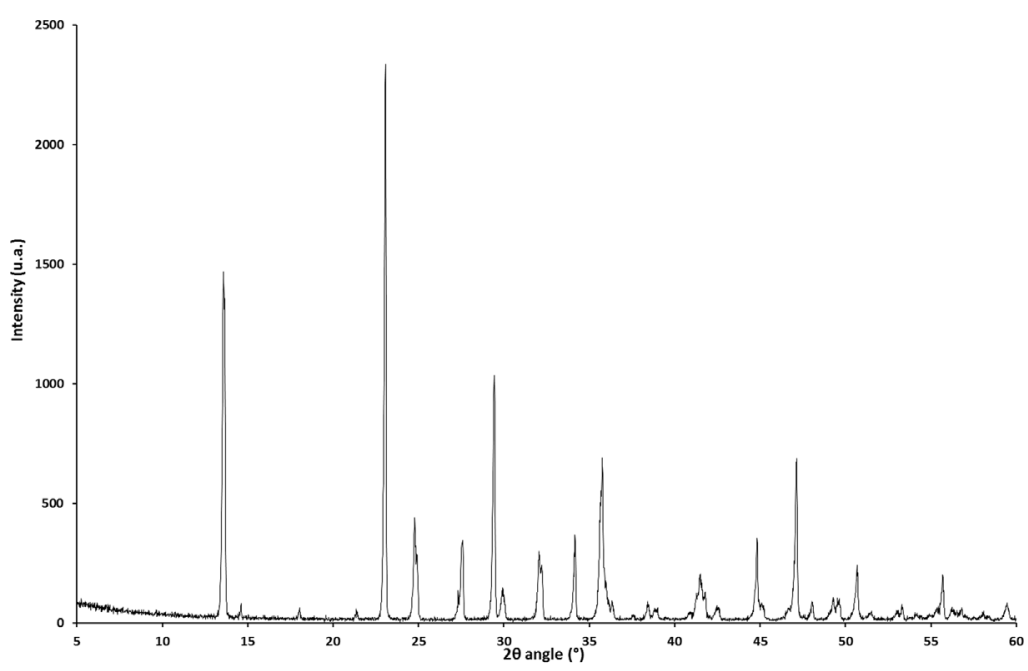

FIGURE 3 | XRD pattern of nesquehonite (synthesis conditions: $25^{\circ} \mathrm{C}, 4 \mathrm{~h}, 0.1 \mathrm{~mol}$ of $\mathrm{MgCl}_{2}$ and $\mathrm{Na}_{2} \mathrm{CO}_{3}$, total volume $1.1 \mathrm{~L}$ ) in agreement with $\mathrm{PDF}$ \#00-020-0669 (differences in intensity could be explained by the preferred orientation of the crystals). 


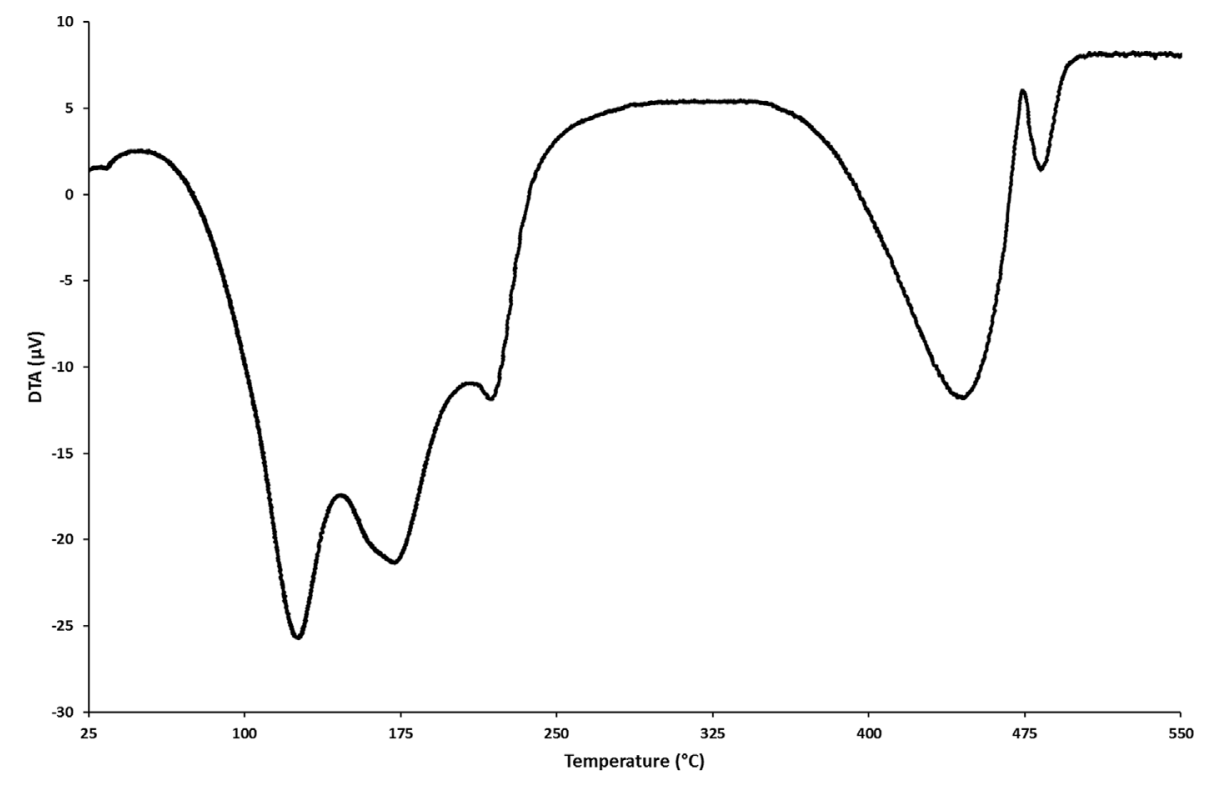

FIGURE 4 | DTA pattern of nesquehonite (synthesis conditions: $25^{\circ} \mathrm{C}, 4 \mathrm{~h}, 0.2 \mathrm{~mol}$ of $\mathrm{MgCl}_{2}$ and $\mathrm{Na}_{2} \mathrm{CO}_{3}$, total volume $1.2 \mathrm{~L}$ ) obtained with a heating

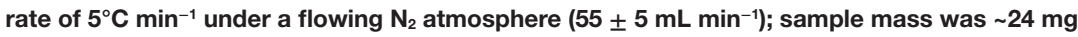

slowly decomposes with the evolution of water and carbon dioxide to a dypingite-like phase, $\mathrm{Mg}_{5}\left(\mathrm{CO}_{3}\right)_{4}(\mathrm{OH})_{2} \cdot n \mathrm{H}_{2} \mathrm{O}$ (with $n>5)$, then to dypingite itself $(n=5)$ and hydromagnesite $(n=4)$. Reaction may require several months to approach completion at room temperature $\left(\sim 20-25^{\circ} \mathrm{C}\right)$ but this delay decreases to only several hours or days in the course of curing under humid conditions at temperatures in the range $60-80^{\circ} \mathrm{C}$.

\section{Preparation and Properties of Nesquehonite-Based Products}

The two methods used for the preparation of nesquehonite-based products are described in Section "Materials and Methods" above. Products are fabricated broadly by the same methods used for clay or cement: a liquid suspension can be poured into molds, or, if using stiffer mixes, compacted in molds by vibration or pressing. Fabrication methods are also important as vibrated and pressed samples typically require less water and could thus achieve higher strengths than cast products. In the case of products prepared with thermally activated nesquehonite, shapes gradually harden as the added water progressively evaporates and part of it is chemically combined to regenerate nesquehonite. In the case of products prepared with the second method, shapes made from nesquehonite gradually gain strength as conversion to dypingite and hydromagnesite occurs which, as explained above, leads to a net loss of structural water and of $\sim 20 \%$ of the $\mathrm{CO}_{2}$ initially sequestered in the solid; however, the $\mathrm{CO}_{2}$ thus released could be looped back to an earlier stage. Both methods result in an extensive microstructural and mineralogical reconstitution, which is the subject of an ongoing study.

Compressive strength values up to $8 \mathrm{MPa}$ were obtained for cubes prepared with both methods, which shows that sufficient strength could be achieved for product applications such as panels and blocks. Measured thermal conductivity values were found to lie in the range $0.21-0.33 \mathrm{~W} \mathrm{~K}^{-1} \mathrm{~m}^{-1}$ for products made from thermally activated nesquehonite; these results, combined with bulk densities in the range $600-900 \mathrm{~kg} \mathrm{~m}^{-3}$, suggest a promising use for the products as thermal insulation materials. For example, a $1 \mathrm{~m} \times 1 \mathrm{~m}, 0.4 \mathrm{~m}$ thick panel (i.e., containing $0.4 \mathrm{~m}^{3}$ of material) with a bulk density of $700 \mathrm{~kg} \mathrm{~m}^{-3}$ will weigh $280 \mathrm{~kg}$ so $\sim 600 \mathrm{~kg}$ less than a comparable panel made of ordinary concrete with a bulk density of $\sim 2200 \mathrm{~kg} \mathrm{~m}^{-3}$, i.e., weighing $\sim 880 \mathrm{~kg}$; since such panel will contain $\sim 30 \mathrm{wt} \%$ carbon dioxide, the amount of $\mathrm{CO}_{2}$ thus sequestered in insulating a typical residential unit would be significant.

\section{DISCUSSION}

\section{MHCH Phases}

Much effort was expended in developing conditions leading to precipitation of phase pure, or nearly pure, nesquehonite. In an industrial context, the source of $\mathrm{CO}_{2}$ could be any flue gas stream, ideally rich in $\mathrm{CO}_{2}$, and the source of $\mathrm{Mg}$ could be a desalination brine. Desalination brines can differ significantly in composition depending on plant design, but for economic reasons the reject water stream is usually not concentrated by more than a factor of $\sim 2$ relative to seawater and is thus close to $1 \mathrm{M} \mathrm{NaCl}$ and $0.1 \mathrm{M} \mathrm{Mg}$; in practice, waste brines are often discharged warm (at $40-45^{\circ} \mathrm{C}$ ). For example, Calera has patented a process for obtaining several specific carbonate phases using seawater as the source of $\mathrm{Mg}$ (Constantz et al., 2010; Camire et al., 2012), but this process is seen as uneconomical due to the high alkali requirements and large seawater volumes needed (Unruh, 2010). 
TABLE 2 | Saturation indexes (SI) of the phases potentially precipitating in the case of the reaction at $25^{\circ} \mathrm{C}$ and $1 \mathrm{~atm}$ of a brine containing $2.4 \mathrm{~g} \mathrm{~L}^{-1}$ $\mathrm{Mg2}^{+}, 23.0 \mathrm{~g} \mathrm{~L}^{-1} \mathrm{Na}^{+}$, and $42.6 \mathrm{~g} \mathrm{~L}^{-1} \mathrm{Cl}^{-}$with a carbonate solution at a $\mathrm{Mg}: \mathrm{CO}_{2}$ molar ratio of 1 ; the initial alkalinity of the system was adjusted to $\mathrm{pH}=7.5$ with $0.1 \mathrm{~g} \mathrm{~L}^{-1} \mathrm{HCO}_{3}^{-}$.

\begin{tabular}{lcrr}
\hline Phase & SI (log IAP-log Ks) & log IAP & Iog Ks \\
\hline Brucite & 6.65 & -4.52 & -11.17 \\
Magnesite & 3.08 & -4.75 & -7.83 \\
Hydromagnesite & 14.38 & -23.96 & -38.34 \\
Nesquehonite & 0.87 & -4.82 & -5.69 \\
\hline
\end{tabular}

The ionic activity products (IAP) and solubility products (Ks) were calculated with PHREEQC (United States Geological Survey, 2015) using the Pitzer database.

Theoretically, the reaction of a brine rich in $\mathrm{Mg}^{2+}$ ions with an effluent from the absorption of $\mathrm{CO}_{2}$ by sodium hydroxide, i.e., a solution of sodium carbonate and bicarbonate, would produce magnesite (Table 2). However, some of the expected phases are kinetically inhibited due to the relatively low temperature of reaction (e.g., hydromagnesite) or the presence of energy barriers (e.g., magnesite). Brucite is also predicted to appear by thermodynamic modeling, but its presence could not be confirmed experimentally due to its expected very low concentration in the solid phase.

Numerous reports of the synthesis of $\mathrm{MHCH}$ phases have been made. Precipitation is mainly done by mixing an aqueous solution of $\mathrm{Mg}$ salts, e.g., $\mathrm{MgCl}_{2}$, with an aqueous solution of $\mathrm{NaHCO}_{3}$ and/or $\mathrm{Na}_{2} \mathrm{CO}_{3}$ (Kloprogge et al., 2003; Haenchen et al., 2008; Case et al., 2011; $\mathrm{Ma}$ and Yoon, 2013). $\mathrm{NaHCO}_{3} /$ $\mathrm{Na}_{2} \mathrm{CO}_{3}$ solutions would be obtained when $\mathrm{NaOH}$ is used for the dissolution of $\mathrm{CO}_{2}$ into an aqueous solution but other bases such as aqueous ammonia solutions have been also used (Ferrini et al., 2009; De Vito et al., 2012). The physical chemistry of the precipitation of $\mathrm{MHCH}$ phases has been much studied and it appears that metastability is widespread among the precipitated products (Dell and Weller, 1959; Bender and Sprague, 1965; Langmuir, 1965; Davies and Bubela, 1973; Canterford et al., 1984; Haenchen et al., 2008; Hopkinson et al., 2008, 2012; Case et al., 2011; Ballirano et al., 2013).

Relatively few uses have been reported for the precipitated $\mathrm{MHCH}$ phases, one possibility being simply to landfill the $\mathrm{MHCH}$. But we sought higher value applications and so developed a process for making self-cementing $\mathrm{MHCH}$ compositions. The choice of $\mathrm{MHCH}$ phase is important as their crystal structures differ especially in the role of "water" and this bonding gives insights into their subsequent potential for self-cementation. Not all the relevant crystal structures are known but two families of $\mathrm{MHCH}$ phases occur: one in which water is present exclusively as molecular water (e.g., nesquehonite) and another in which "water" occurs as mixtures of molecular water and charge-balancing $\mathrm{OH}$ groups (e.g., hydromagnesite). Some contention arises about the structure of nesquehonite because partial structural information, for example, derived from FTIR patterns, has been interpreted in terms of bonding and purport to show that "water" in nesquehonite is present partly as a mixture of molecular water and $\mathrm{OH}$ groups (Hales et al., 2008; Frost and Palmer, 2011; Hopkinson et al., 2012). However, the X-ray crystal structure shows unequivocally that species such as $\mathrm{HCO}_{3}^{-}$and $\mathrm{OH}^{-}$are absent: the correct picture is that all protons are combined as water in nesquehonite
(Stephan and MacGillavry, 1972; Giester et al., 2000). The binding state of the "water" in the phases is important as it affects their subsequent evolution in the course of thermal treatment and enables control over the development of cementitious properties: so far, only nesquehonite (i.e., an $\mathrm{MHCH}$ phase containing only molecular water) was found to develop cementitious properties when treated, as described above.

\section{Next Steps}

Much work has been done on the relationships between porosity and microstructure but without as yet gaining a full understanding of the complex relationships. From the low bulk densities obtained (usually $600-900 \mathrm{~kg} \mathrm{~m}^{-3}$ ) and the densities of the solid phases $\left(1840 \mathrm{~kg} \mathrm{~m}^{-3}\right.$ for nesquehonite and $2240 \mathrm{~kg} \mathrm{~m}^{-3}$ for hydromagnesite), the porosity of the products is high, typically around $60 \%$. Despite that, strength remains relatively high. Characterization data and a mechanistic account of the relationships between porosity, permeability, and strength will be presented in a subsequent paper.

We have published a preliminary study of the GHG balance of the process (Galvez-Martos et al., 2016); in this study, it is shown that the carbon footprint of the developed product only becomes negative when the carbon footprint of other construction materials that are replaced, such as gypsum plasterboard, is taken into account.

One of the key economic costs associated with the process is the relatively high cost of the sodium hydroxide required to run the process. Further optimization, aiming to minimize alkali consumption, is therefore necessary: we have started to search for other means of adjusting the $\mathrm{pH}$ in the course of the $\mathrm{CO}_{2}$ dissolution and $\mathrm{MHCH}$ precipitation stages.

We are presently beginning the design of a pilot plant for making nesquehonite to be located in Qatar. The intention is to use reject desalination brines from a nearby desalination plant as the source of magnesium and to capture $\mathrm{CO}_{2}$ from a diesel engine exhaust (the engine is operated for an entirely unrelated process and its exhaust would normally be discharged into the atmosphere). It is anticipated that the pilot plant will be commissioned in mid-2016. The experience thus gained will be used to evaluate product properties and process economics: actual operational experience will be used to get a much firmer estimate of cost, including a more realistic costing of capital investment. It is also intended to make an actual demonstration of a construction using products from the pilot plant.

\section{Other Developments}

Significant progress has been reported in using Mg-containing minerals, e.g., periclase, magnesite, olivine, or serpentine, as targets for mineral sequestration. Several minerals are responsible for the observed $\mathrm{CO}_{2}$ capture but, using thermally activated serpentine rocks, nesquehonite is almost invariably observed to form in the course of the reaction of the activated rocks at ambient temperature with water and carbon dioxide; serpentine will therefore be considered to be an important target phase for sourcing $\mathrm{Mg}$.

Until now, we have considered that we will have to make nesquehonite and, to that end, have developed precipitation routes from aqueous sources. These sources, which can be terrestrial as 
well as marine, would include formation waters or production brines from the oil and gas industry.

However, the formation of nesquehonite-based cementitious products is essentially a free-standing process, independent of the source of nesquehonite or $\mathrm{Mg}$. It is therefore apparent that a process based on Mg-containing rocks, formation waters, or production brines could be adapted so as to produce an aqueous stream suitable for the precipitation of nesquehonite in relatively phase pure form. This would enable useful solids to be obtained as by-products of the sequestration process, thus elevating the sequestration products from wastes to useful, value-added construction materials.

\section{REFERENCES}

Ballirano, P., De Vito, C., Ferrini, V., and Mignardi, S. (2010). The thermal behaviour and structural stability of nesquehonite, $\mathrm{MgCO}_{3} \cdot 3 \mathrm{H}_{2} \mathrm{O}$, evaluated by in situ laboratory parallel-beam X-ray powder diffraction: new constraints on $\mathrm{CO}_{2}$ sequestration within minerals. J. Hazard. Mater. 178, 522-528. doi:10.1016/j. jhazmat.2010.01.113

Ballirano, P., De Vito, C., Mignardi, S., and Ferrini, V. (2013). Phase transitions in the $\mathrm{Mg}-\mathrm{CO}_{2}-\mathrm{H}_{2} \mathrm{O}$ system and the thermal decomposition of dypingite, $\mathrm{Mg}_{5}\left(\mathrm{CO}_{3}\right)_{4}(\mathrm{OH})_{2} \cdot 5 \mathrm{H}_{2} \mathrm{O}$ : implications for geosequestration of carbon dioxide. Chem. Geol. 340, 59-67. doi:10.1016/j.chemgeo.2012.12.005

Bender, M., and Sprague, R. S. (1965). The preparation and structure of magnesium carbonate trihydrate2. J. Inorg. Nucl. Chem. 27, 1872-1873. doi:10.1016/0022-1902(65)80335-9

Camire, C., Lu, P., Kendall, T. and Devenney, M. (2012). Methods and Products Utilising Magnesium Oxide for Carbon Dioxide Sequestration. Patent US20120291675.

Canterford, J. H., Tsambourakis, G., and Lambert, B. (1984). Some observations on the properties of dypingite, $\mathrm{Mg}_{5}\left(\mathrm{CO}_{3}\right)_{4}(\mathrm{OH})_{2} \cdot 5 \mathrm{H}_{2} \mathrm{O}$, and related minerals. Mineral. Mag. 48, 437-442. doi:10.1180/minmag.1984.048.348.15

Case, D. H., Wang, F., and Giammar, D. E. (2011). Precipitation of magnesium carbonates as a function of temperature, solution composition, and presence of a silicate mineral substrate. Environ. Eng. Sci. 28, 881-889. doi:10.1089/ ees. 2010.0341

Constantz, B. R., Youngs, A., and Holland, T. C. (2010). $\mathrm{CO}_{2}$-Sequestering Formed Building Materials. Patent WO2010039903.

Davies, P. J., and Bubela, B. (1973). The transformation of nesquehonite into hydromagnesite. Chem. Geol. 12, 289-300. doi:10.1016/0009-2541(73)90006-5

De Vito, C., Ferrini, V., Mignardi, S., Cagnetti, M., and Leccese, F. (2012). Progress in carbon dioxide sequestration via carbonation of aqueous saline waste. Period. Miner. 81, 333-344. doi:10.2451/2012PM0019

Dell, R. M., and Weller, S. W. (1959). The thermal decomposition of nesquehonite $\mathrm{MgCO}_{3} \cdot 3 \mathrm{H}_{2} \mathrm{O}$ and magnesium ammonium carbonate $\mathrm{MgCO}_{3} \cdot\left(\mathrm{NH}_{4}\right)_{2} \mathrm{CO}_{3} \cdot 4 \mathrm{H}_{2} \mathrm{O}$. Trans. Faraday Soc. 55, 2203-2220. doi:10.1039/tf9595502203

Earth System Research Laboratory. (2016). Global Monitoring Division, Mauna Loa Observatory, Trends in Atmospheric Carbon Dioxide. Available at: http://www. esrl.noaa.gov/gmd/ccgg/trends (accessed January 2016).

Ferrini, V., De Vito, C., and Mignardi, S. (2009). Synthesis of nesquehonite by reaction of gaseous $\mathrm{CO}_{2}$ with $\mathrm{Mg}$ chloride solution: its potential role in the sequestration of carbon dioxide. J. Hazard. Mater. 168, 832-837. doi:10.1016/j. jhazmat.2009.02.103

Frost, R. L., and Palmer, S. J. (2011). Infrared and infrared emission spectroscopy of nesquehonite $\mathrm{Mg}(\mathrm{OH})\left(\mathrm{HCO}_{3}\right) \cdot 2 \mathrm{H}_{2} \mathrm{O}$ - implications for the formula of nesquehonite. Spectrochim. Acta A 78, 1255-1260. doi:10.1016/j. saa.2010.12.059

Galvez-Martos, J. L., Morrison, J., Jauffret, G., Elsarrag, E., Al-Horr, Y., Imbabi, M. S., et al. (2016). Environmental assessment of aqueous alkaline absorption of carbon dioxide and its use to produce a construction material. Resourc. Conservat. Recycl. 107, 129-141. doi:10.1016/j.resconrec.2015.12.008

Giester, G., Lengauer, C. L., and Rieck, B. (2000). The crystal structure of nesquehonite, $\mathrm{MgCO}_{3} \cdot 3 \mathrm{H}_{2} \mathrm{O}$, from Lavrion, Greece. Mineral. Petrol. 70, 153-163. doi: $10.1007 / \mathrm{s} 007100070001$

\section{AUTHOR CONTRIBUTIONS}

FG directed the preparation of the paper. FG and MI directed the work carried out by GJ, JM, J-LG-M, and NP.

\section{ACKNOWLEDGMENTS}

The work described here was supported financially by GORD, the Gulf Organisation for Research and Development, based in Doha, Qatar. It forms part of the "Green Concrete" project at the University of Aberdeen.

Global CCS Institute. (2016). Large Scale CCS Projects (Overview, Map \& Database). Available at: http://www.globalccsinstitute.com/projects/ large-scale-ccs-projects (accessed January 2016).

Haenchen, M., Prigiobbe, V., Baciocchi, R., and Mazzotti, M. (2008). Precipitation in the $\mathrm{Mg}$-carbonate system - effects of temperature and $\mathrm{CO}_{2}$ pressure. Chem Eng. Sci. 63, 1012-1028. doi:10.1016/j.ces.2007.09.052

Hales, M. C., Frost, R. L., and Martens, W. N. (2008). Thermo-Raman spectroscopy of synthetic nesquehonite - implication for the geosequestration of greenhouse gases. J. Raman Spectrosc. 39, 1141-1149. doi:10.1002/jrs.1950

Haywood, H. M., Eyre, J. M., and Scholes, H. (2001). Carbon dioxide sequestration as stable carbonate minerals - environmental barriers. Environ. Geol. 41, 11-16. doi:10.1007/s002540100372

Hopkinson, L., Kristova, P., Rutt, K., and Cressey, G. (2012). Phase transitions in the system $\mathrm{MgO}-\mathrm{CO}_{2}-\mathrm{H}_{2} \mathrm{O}$ during $\mathrm{CO}_{2}$ degassing of $\mathrm{Mg}$-bearing solutions. Geochim. Cosmochim. Acta 76, 1-13. doi:10.1016/j.gca.2011.10.023

Hopkinson, L., Rutt, K., and Cressey, G. (2008). The transformation of nesquehonite to hydromagnesite in the system $\mathrm{CaO}-\mathrm{MgO}-\mathrm{H}_{2} \mathrm{O}-\mathrm{CO}_{2}$ : an experimental spectroscopic study. J. Geol. 116, 387-400. doi:10.1086/588834

Hull, T. R., Witkowski, A., and Hollingbery, L. (2011). Fire retardant action of mineral fillers. Polym. Degrad. Stab. 96, 1462-1469. doi:10.1016/j. polymdegradstab.2011.05.006

Jauffret, G., Morrison, J., and Glasser, F. P. (2015). On the thermal decomposition of nesquehonite. J. Therm. Anal. Calorim. 122, 601-609. doi:10.1007/ s10973-015-4756-0

Kloprogge, J. T., Martens, W. N., Nothdurft, L., Duong, L. V., and Webb, G. E. (2003). Low temperature synthesis and characterization of nesquehonite. J. Mater. Sci. Lett. 22, 825-829. doi:10.1023/A:1023916326626

Lackner, K. S. (2002). Carbonate chemistry for sequestering fossil carbon. Annu. Rev. Energy Environ. 27, 193-232. doi:10.1146/annurev.energy.27.122001.083433

Lanas, J., and Alvarez, J. I. (2004). Dolomitic lime: thermal decomposition of nesquehonite. Thermochim. Acta 421, 123-132. doi:10.1016/j.tca.2004.04.007

Langmuir, D. (1965). Stability of carbonates in the system $\mathrm{MgO}-\mathrm{CO}_{2}-\mathrm{H}_{2} \mathrm{O}$. J. Geol. 73, 730-754. doi:10.1086/627113

$\mathrm{Ma}$, J., and Yoon, R. H. (2013). Use of reactive species in water for $\mathrm{CO}_{2}$ mineralisation. Energy Fuels 27, 4190-4198. doi:10.1021/ef400201a

Mazzotti, M., Abanades, J. C., Allam, R., Lackner, K. S., Meunier, F., Rubin, E., et al. (2005). "Mineral carbonation and industrial uses of carbon dioxide," in IPCC Special Report on Carbon dioxide Capture and Storage (New York: Cambridge University Press), 319-338.

Morgan, B., Wilson, S. A., Madsen, I. C., Gozukara, Y. M., and Habsuda, J. (2015). Increased thermal stability of nesquehonite $\left(\mathrm{MgCO}_{3} \cdot 3 \mathrm{H}_{2} \mathrm{O}\right)$ in the presence of humidity and $\mathrm{CO}_{2}$ : implications for low-temperature $\mathrm{CO}_{2}$ storage. Int. J. Greenhouse Gas Control 39, 366-376. doi:10.1016/j.ijggc.2015.05.033

Morrison, J., Jauffret, G., Glasser, F. P., Galvez-Martos, J. L. and Imbabi, M. S. (2014). "Towards carbon negative cements", in Proceedings of the $34^{\text {th }}$ Annual Cement and Concrete Science Conference and Workshop on Waste Cementation (Sheffield: IOM3), 23-25.

Olajire, A. A. (2013). A review of mineral carbonation technology in sequestration of $\mathrm{CO}_{2}$. J. Petrol. Sci. Eng. 109, 364-392. doi:10.1016/j.petrol.2013.03.013

Stephan, G. W., and MacGillavry, C. H. (1972). The crystal structure of nesquehonite, $\mathrm{MgCO}_{3} \cdot 3 \mathrm{H}_{2} \mathrm{O}$. Acta Crystallogr. B 1972, 1031-1033. doi:10.1107/ S0567740872003668 
Styring, P., Jansen, D., de Coninck, H., Reith, H. and Armstrong, K. (2011). Carbon Capture and Utilization in the Green Economy. Report No. 501. Sheffield: The Centre for Low Carbon Futures 2011 and CO2Chem Publishing 2012.

Teir, S., Kuusik, R., Fogelholm, C. J., and Zevenhoven, R. (2007). Production of magnesium carbonates from serpentinite for long-term storage of $\mathrm{CO}_{2}$. Int. J. Miner. Process. 85, 1-15. doi:10.1016/j.minpro.2007.08.007

Tleoubaev, A., and Brzezinski, A. (2008). "Errors of the heat flow meter method caused by thermal contact resistance," in Proceedings of the 29th International Thermal Conductivity Conference, ITCC29 and Proceedings of the 17th International Thermal Expansion Symposium, ITES17 (Birmingham: Destech Publications Inc.), 465-473.

United States Geological Survey. (2015). PHREEQC (Version 3) - A Computer Program for Speciation, Batch-Reaction, One-Dimensional Transport, and Inverse Geochemical Calculations. Available at: http://wwwbrr.cr.usgs.gov/ projects/GWC_coupled/phreeqc/ (accessed December 2015).

Unluer, C., and Al-Tabbaa, A. (2013). Impact of hydrated magnesium carbonate additives on the carbonation of reactive MgO cements. Cem. Concr. Res. 54, 87-97. doi:10.1016/j.cemconres.2013.08.009
Unruh, J. (2010). Calera Corporation's Presumed Carbon Capture and Sequestration Process. Available at: www.energytrendsinsider.com (accessed September 2015).

Vagvolgyi, V., Hales, M., Frost, R. L., Locke, A., Kristof, J., and Horvath, E. (2008). Conventional and controlled rate thermal analysis of nesquehonite $\mathrm{Mg}\left(\mathrm{HCO}_{3}\right)(\mathrm{OH}) \cdot 2\left(\mathrm{H}_{2} \mathrm{O}\right)$. J. Therm. Anal. Calorim. 94, 523-528. doi:10.1007/ s10973-007-8844-7

Conflict of Interest Statement: The authors declare that the research was conducted in the absence of any commercial or financial relationships that could be construed as a potential conflict of interest.

Copyright (c) 2016 Glasser, Jauffret, Morrison, Galvez-Martos, Patterson and Imbabi. This is an open-access article distributed under the terms of the Creative Commons Attribution License (CC BY). The use, distribution or reproduction in other forums is permitted, provided the original author(s) or licensor are credited and that the original publication in this journal is cited, in accordance with accepted academic practice. No use, distribution or reproduction is permitted which does not comply with these terms. 